with duration of positive symptoms. This work, as well as the phosphorus work by our team (Jensen et al, 2000, 2002), suggests a gradual neurodegenerative process in the anterior cingulate in schizophrenia, possibly initiated by an early neurodevelopmental anomaly involving basal ganglia-thalamocortical neuronal circuits or the structures which regulate these circuits. As Dr Rands points out, memantine would partially block the NMDA receptors preventing excitotoxic damage in the anterior cingulate and connected structures, thus slowing the progression of symptoms. However, there are other considerations. There is evidence that excitotoxicity is linked to non-NMDA receptors (Tsai \& Coyle, 2002) which may not be affected by this approach. Furthermore, another NMDA-blocker, phencyclidine, can actually cause a paradoxical increase in glutamate activity which could aggravate the condition.

In summary, we agree that treatment options for schizophrenia should begin to focus more on this neuroprotective strategy. Although current medications may alleviate positive symptoms, they are relatively ineffective for negative symptoms and are often inadequate in preventing the psychosocial deterioration seen in chronic schizophrenia. Treatment with memantine could theoretically slow the progression of negative symptoms when administered to patients in the early stages of schizophrenia but the overall effects of these drugs are difficult to predict and it is our view that some caution is indicated in planning long-term trials of these medications in people with schizophrenia.

Jensen, J. E., Miller, J., Williamson, P. C., et al (2000) Focal changes in brain energy and phospholipid metabolism in first-episode schizophrenia: ${ }^{31}$ P-MRS chemical shift imaging study at 4 Tesla. British Journal of Psychiatry, 184, 409-4I5.

Jensen, J. E., AI-Semaan, Y. M., Williamson, P. C., et al (2002) Region-specific changes in phospholipids metabolism in chronic, medicated schizophrenia: ${ }^{31} \mathrm{P}$ MRS study at 4.0 Tesla. British Journal of Psychiatry, 180 39-44.

Theberge, J., Bartha, R., Drost, D. J., et al (2002) Glutamate and glutamine measured with $4.0 \mathrm{~T}$ proton MRS in never-treated patients with schizophrenia and healthy volunteers. American Journal of Psychiatry, I59. 1944-1946.

Theberge, J., Al-Semaan, Y., Williamson, P. C., et al (2003) Glutamate and glutamine in the anterior cingulate and thalamus of medicated patients with chronic schizophrenia and healthy comparison subjects measured with 4.0-T proton MRS. American Journal of Psychiatry, 160, 2231-2233.
Tsai, G. \& Coyle, J.T. (2002) Glutamatergic mechanisms in schizophrenia. Annual Review of Pharmacology and Toxicology, 42, 165-179.

J. E. Jensen Room 208, Brain Imaging Center McLean Hospital, II5 Mill Street, Belmont, MA 02478-9106, USA

E-mail: ejensen@mclean.harvard.edu

J. Miller, P. C. Williamson, R.W. J. Neufeld, R. S. Menon University of Western Ontario, Canada

A. Malla McGill University, Montreal, Canada

R. Manchanda, B. Schaefer University of Western Ontario, Canada

M. Densmore, D. J. Drost St Joseph's Health Care, London, Ontario, Canada

\section{Testing for diabetes}

Taylor et al (2004) report on the differences in testing for diabetes among 606 patients receiving antipsychotics, observing that patients receiving atypical antipsychotics were more likely to have been tested than those receiving older agents. Moreover, this appeared to be significant specifically for clozapine, olanzapine, and antipsychotic polypharmacy.

It is noteworthy that very similar results were found by our group when examining hospitalised patients in New York State (Citrome et al, 2003, 2004). Among 1154 patients in 2000-2002 with no known prior history of receiving antidiabetic medications, those receiving clozapine, olanzapine, or more than one atypical antipsychotic had a significantly higher frequency of blood glucose testing than those receiving only typical antipsychotics (Citrome et al, 2004). Moreover, those receiving risperidone had a frequency of testing similar to those receiving only older agents, resulting in the conclusion that there are clear differences in surveillance for diabetes mellitus among even the newer agents.

Investigators performing pharmacoepidemiological studies examining the risk of association between antipsychotics and diabetes mellitus need to be mindful of this surveillance bias.

\section{Declaration of interest}

L.C. has received research support and/or honoraria for speaking on advisory boards from Abbott, Astra Zeneca, Bristol Myers Squibb, Eli Lilly, Janssen, Novartis, Pfizer and Repligen Corp. A.J. has received research support from Eli Lilly.
Citrome, L., Jaffe, A., Levine, J., et al (2003) Antipsychotic medication treatment and new prescriptions for insulin and oral hypoglycaemics. European Neuropsychopharmacology, I3 (suppl. 4), S306.

Citrome, L., Jaffe, A., Levine, J., et al (2004) Relationship between antipsychotic medication treatment and new cases of diabetes among psychiatric inpatients. Psychiatric Services, 55, 1006-1013.

Taylor, D., Young, C., Esop, R., et al (2004) Testing for diabetes in hospitalised patients prescribed antipsychotic drugs. British Journal of Psychiatry, 185, 152-156.

L. Citrome, A. Jaffe, J. Levine New York University School of Medicine, Department of Psychiatry, Nathan Kline Institute for Psychiatric Research, 140 Old Orangeburg Road, Orangeburg NY 10962, USA

Taylor et al (2004) found very low rates of monitoring for diabetes in their study population. Less than $50 \%$ were tested, and the testing rates varied with the antipsychotic prescribed.

So why is this the case? This probably reflects the lack of a clear consensus in this area. There is currently no consistent direction for doctors regarding the need for monitoring for diabetes. The conflicting evidence in the literature is abundant. For example, the British National Formulary is probably the most widely used reference for prescribers in the UK. The current edition makes no mention of blood sugar abnormalities with typical antipsychotics, quetiapine and risperidone. Concerns are mainly highlighted with olanzapine and clozapine. This is despite studies showing increased risks with typical and atypical antipsychotics. Furthermore, the recent Maudsley Guidelines give some suggestions of the type and frequency of tests, focus mainly on olanzapine and clozapine but contradict the British National Formulary in suggesting testing for all antipsychotics.

So is testing important? Evidence is mounting of an association between schizophrenia and diabetes. Ryan \& Thakore (2002) give schizophrenia as an independent risk factor for diabetes even in antipsychotic-naïve patients. The PORT study (Dixon et al, 2000) gives a prevalence of $15 \%$ in this population compared with $3 \%$ in the general population (Bennett et al, 1995). Several studies suggest an even higher risk of diabetes in those prescribed atypical antipsychotics (Bushe \& Leonard, 2004). Therefore, it appears that people with schizophrenia are a high-risk group for developing diabetes and its potential consequences. 
Our patients may have little contact with other doctors and diabetes can be a silent illness which could be easily missed. Psychiatrists are well placed to monitor this high-risk population and should be encouraged to adopt a holistic approach. There is a need for clear consensus to avoid any confusion among psychiatrists. Guidelines are needed to help clinicians to decide which patients should be tested, the type of test to use and how often. The Royal
College of Psychiatrists is well placed to publish the necessary guidelines.

Bennett, N., Dodd, T., Flatley, J., et al (1995) Health Survey for England 1993. London: HMSO.

Bushe, C. \& Leonard, B. (2004) Association between atypical antipsychotic agents and type 2 diabetes: review of prospective clinical data. British Journal of Psychiatry, 184 (suppl. 47), s87-s93.

Dixon, L., Weiden, P., Delahanty, J., et al (2000)

Prevalence and correlates of diabetes in national schizophrenia samples. Schizophrenia Bulletin, 26 , 903-912.

Ryan, M. C. M. \& Thakore, J. H. (2002) Physical consequences of schizophrenia and its treatment: the metabolic syndrome. Life Sciences, 7I, 239-257.

Taylor, D., Young, C., Esop, R., et al (2004) Testing for diabetes in hospitalised patients prescribed antipsychotic drugs. British Journal of Psychiatry, 185, 152-156.

P. Brook Birmingham and Solihull Mental Health NHS Trust, Lyndon Clinic, Hobs Meadow, Solihull B92 8PW, UK

\section{One hundred years ago}

\section{The asylum medical service}

\section{To the Editors of THE LANCET}

SIRS, - I am glad to see by the letter of "M.B." in your issue of Dec. 31st, 1904, p. 1888 , that at least one assistant medical officer has the courage to protest against the treatment which is meted out to his colleagues in the asylum service. The present unsatisfactory state of affairs has gone on quite long enough and in the interest not only of the medical staff but also of the patients committed to their charge a change is desirable, even essential. As long as the medical staffs of asylums are content to exist under their present conditions it is useless to insinuate that the fault lies at the door of those in authority, be they Commissioners in Lunacy, visiting committees, or even medical superintendents. The fault and the remedy lie in their own hand. But how few will ever take the trouble to place their views on paper. There are three distinct classes of assistant medical officers in asylums: (1) those who on entering it intend to remain in the service, devoting their lives to the study and treatment of mental diseases and thus in time becoming specialists; (2) those who, newly qualified, seek an asylum appointment in order that they may read for some further examination, on the passing of which they have set their ambition; or (3), those who unable to afford to enter general practice immediately they become qualified take an asylum post with the intention of waiting for a suitable opening in some district which may be known to them. When the opportunity presents itself they leave and are succeeded by colleagues with possibly similar views. To such as these an asylum appointment is but a means to an end. The end having been attained they depart and as a rule trouble no more about lunacy or asylums unless they be called on to certify a patient in the course of their general practice.

In the case of an assistant medical officer who enters the asylum service with the intention of remaining permanently in it the case is very different. He starts full of enthusiasm and hope with an initial salary of anything from $£ 120$ to $£ 150$ per annum with the usual allowances. Three or four years pass by and he finds himself with some knowledge of mental diseases in addition to the general knowledge of his profession with which he started, but it suddenly occurs to him that notwithstanding his increased experience in a special science he is still drawing the same salary as when he entered the asylum service fresh from the hospital. His colleagues who are senior to him have little, if any, prospect of promotion in the future. True, they have had more years of service and consequent experience, but their salaries are very little in excess of what was considered sufficient remuneration for him when he entered the service without any special knowledge of lunacy. Then come weary years of waiting, hoping that one of his seniors may be promoted to one of the few vacant medical superintendencies which may chance to occur at rare intervals, and in most cases with resulting disappointment. His senior colleague, should he be unsuccessful in obtaining the post of medical superintendent in some other asylum, is in, if possible, a more hopeless plight. He has given the best years of his life to the study of mental diseases. What is his reward? A salary of perhaps $£ 250$ or $£ 300$ per annum and should he be over 40 years of age the probability that he may expect no further promotion or increase of salary. Moreover, there is a rule that no assistant medical officer can be married. (I believe there are one or two cases in which the senior assistant medical officer can do so if he likes.)

To the junior members of the staff, this is not such a hardship as to their seniors. The pay and accommodation of a junior assistant medical officer put matrimony out of the question but when a senior comes to the age of, say, 40 years he may have some desire to have a home of his own after living for years in two rooms. With all respect for the authorities who govern asylums I would ask, What has a man done who has given the best years of his life to their service that he should be debarred from entering the matrimonial state should he so desire? As far as I can ascertain there is no other branch of the public service in which such a restriction is imposed on the permanent medical staff. It may be argued by those who favour the present system of enforced celibacy in the case of asylum assistant medical officers that a similar rule is in force in the hospitals and Poor-law infirmaries. To them I would point out that in neither case do the medical officers accept their appointments as a permanency. They, as a rule, leave after longer or shorter periods and enter general 